\title{
Do Medo do Crime à Rebelião: Algumas Indicações para Pensar a Experiência Coletiva Brasileira a partir da Filosofia de Spinoza
}

From Fear for Crime to Rebellion: Some Indications to Think Brazilian Collective Experience From the Point of View of the Philosophy of Spinoza

Del Miedo al Crimen a la Rebelión: Algunas Indicaciones para Pensar la Experiencia Colectiva Brasileira a Partir de la Filosofía de Spinoza

\section{Cristina Mair Barros Rauter}

Universidade Federal Fluminense, Niteroi, RJ, Brasil.

\begin{abstract}
Resumo
Partindo do medo do crime como fenômeno da cena brasileira contemporânea, discutimos ao afeto de medo na filosofia de Spinoza, examinando suas possibilidades de transformação noutros afetos e suas relações de vizinhança com a rebelião. Os limites da ação dos dispositivos de controle social contemporâneos são analisados a partir do funcionamento dos afetos humanos, tomados simultaneamente como constituintes da multidão.
\end{abstract}

Palavras-chave: Medo; Crime; Coletivo

\begin{abstract}
Departing from the fear for crime as a phenomenon of Brazilian contemporary scene, we discuss the affection of fear in the philosophy of Spinoza, in its possibilities of transformation into other kinds of affects and in its relations with rebellion. The limits of social control devices are analyzed from the point of view of human affective live, taken simultaneously as constitutive of the multitude.
\end{abstract}

Keywords: Fear; Crime; Collective

\section{Resumen}

A partir del miedo al crimen como un fenómeno de la escena brasileira contemporánea, discutimos el afecto del miedo en la filosofía de Spinoza en sus posibilidades de trasformación en otros tipos de afecto y en sus relaciones con la rebelión. Los límites de los dispositivos de control social contemporáneos son analizados desde el punto de vista de la vida afectiva humana, simultáneamente como constitutivos de la multitud.

Palabras clave: Miedo; Crimen; Coletivo 
$\mathrm{O}$ medo à criminalidade é um fenômeno que atravessa a experiência coletiva brasileira. Denominamos "dispositivo da criminalização" (Rauter, 2009), uma engrenagem da qual fazem parte a mídia, em sua obsessiva veiculação diária de fatos tristes e violentos, a instituição policial, o judiciário, o sistema prisional ... No capitalismo atual experimentamos uma vida social extremamente rica, com cidades populosas e uma interdependência complexa no campo do trabalho e ao mesmo tempo, parte dessa complexidade é reduzida em sua potencialidade política por múltiplos dispositivos: midiáticos, policiais, carcerários, pedagógicos, entre outros, funcionando em rede. Consideramos que a ação desse dispositivo é central para uma compreensão dos processos de subjetivação no Brasil. Um de seus efeitos é a disseminação do medo - medo de sair à rua, medo de sentar numa praça ou num jardim, com frequência cercado por grades, medo de entrar num ônibus à noite, e assim por diante. Constatamos que noutro momentos, o medo parece ter desaparecido, quando, por exemplo, desde junho de 2013, multidões vão às ruas para manifestações ou durante o carnaval.

Spinoza pode trazer para a Psicologia Social importantes ferramentas para a compreensão de fenômenos político-institucionais ao incluir os afetos na política, construindo uma zona de intercessão entre Rev. Polis e Psique, 2013;3(2):151-161 a Psicologia Clínica e a Psicologia Social, numa análise em que estes deixam de ser fenômenos da interioridade psicológica e passam a ser analisados na superfície. Por outro lado, ao invés de desqualificar os afetos humanos, como ocorre na tradição cartesiana ou hobbesiana, Spinoza vê neles a matéria a partir do qual pode ser compreendida a vida coletiva.

Para Spinoza, o medo corresponde a variação para menos da potência. É um dos afetos que podem ser chamados de "afetos tristes”. Já a variação para mais da potência corresponde a alegrias de vários tipos: a esperança, o contentamento, o júbilo, etc. Tal variação afetiva decorre dos encontros que fazemos com coisas e pessoas, com objetos do mundo; provém, portanto, da experiência. Uma das expressões do medo coletivo é o afeto triste de submissão. Quanto pode durar a submissão que experiência do medo coletivo produz? Seria possível escapar dos efeitos produzidos pelas pílulas diárias de medo ministradas pelos meios de comunicação ou que experimentamos ao passarmos por uma viatura policial com os canos das armas à mostra, ou simplesmente à passagem da polícia, por sabermos de fatos como balas perdidas, assassinatos de inocentes pelo simples fato de não pararem numa barreira policial, entre outros?

Pensamos que o dispositivo da criminalização faz disseminar no campo social 
um medo difuso cujo resultado pode ser o esvaziamento do coletivo no sentido político - um esvaziamento dos laços horizontais que os indivíduos podem estabelecer entre si.

Examinemos, à luz da filosofia de Spinoza, o funcionamento dos afetos humanos. Estes são, para Spinoza, variáveis e imprevisíveis como as ondas do mar ou os fenômenos metereologicos (Spinoza, Tratado Político, I, prop.4). Essa variação é tomada por Hobbes como algo negativo: o reino dos afetos seria o reino da incerteza ou da violência de todos contra todos. A verdadeira política seria a política do estado, praticada por especialistas, os políticos. As coletividades humanas, sujeitas aos afetos e à oscilação que eles trazem, demandariam sempre uma organização superior para geri-las. Já para a tradição cartesiana, conhecer é afastar-se da vida afetiva, depurar o objeto a ser conhecido dessa interferência. Porém Spinoza segue outra direção, conferindo positividade à experiência afetiva humana tanto como uma via para o conhecimento quanto para a política.

Para Spinoza não há nada mais valioso e útil para um homem do que outro homem, porém eles pouco podem aproveitar dessa utilidade, já que com muita frequência se tornam mutuamente nocivos. É necessário lembrar que utilidade, para Spinoza, tem um sentido bem diferente do que comumente damos à palavra, ligando-a à realização de um fim. Em Spinoza, o útil é o que concorre para a ampliação de nossa potência.

\begin{abstract}
É útil ao homem aquilo que dispõe o seu corpo a poder ser afetado de muitas maneiras ou que o torna capaz de afetar de muitas maneiras os corpos exteriores; é tanto mais útil quanto mais torna o corpo humano capaz de ser afetado e de afetar os outros corpos de muitas maneiras. E [...] nocivo aquilo que torna o corpo menos capaz disso. (Ética IV, prop. 38)
\end{abstract}

Quando dois indivíduos se juntam, eles compõem um indivíduo duas vezes mais potente do que cada um deles considerado separadamente. Nesta medida, para Spinoza, nada é mais útil ao homem do que outro homem. "Nada é mais vantajosos aos homens para conservar o seu ser do que estarem em concordância, como se formassem um só corpo, uma só mente, buscando juntos o que é de utilidade comum para todos" (Tratado Político, III, prop. 7). Essa possibilidade de formar com outros indivíduos um só corpo, uma só mente, é reafirmada por Spinoza no Tratado Político. Ela nasce da capacidade que temos de nos contagiar com os afetos dos nossos semelhantes. Essa capacidade de contagio afetivo com o semelhante é a essência do conceito de multidão, que aparece na última obra de Spinoza, o Tratado Político. 
A imaginação é o cimento que une os homens entre si. No entanto, é também pela via da imaginação que os maiores enganos podem ser cometidos. Como seria possível enxergar no funcionamento dos afetos dos indivíduos a potência humana? Uma certa tradição no campo das ciências humanas, em especial no campo da criminologia, nos diz que nos grupos os homens se comportam como crianças ou como criminosos, que são incapazes de controlar sua afetividade desordenada, que seria controlada apenas pelo líder ou pelas instituições, pelo judiciário ou pela polícia, que com suas regras os modelariam do exterior. Porém essas ideias não se coadunam com o ponto de vista trazido por Spinoza, no qual a potência emerge a partir da multiplicidade de encontros de que um indivíduo é capaz. Para Spinoza, seremos tanto mais potentes quanto mais encontros fizermos. A noção de indivíduo, em Spinoza, está ligada à noção de multiplicidade. Um indivíduo é sempre composto de um grande número de indivíduos. Um grupo é também um indivíduo composto por múltiplos indivíduos, um estado, um país ... o universo inteiro. Numa compreensão da qual a noção de transversalidade (Deleuze e Guattari, 1976, p. 47) é herdeira, o conceito de indivíduo, pensado a partir desta filosofia, pode trazer para o campo da psicologia a possibilidade abordar simultaneamente os fenômenos político-insRev. Polis e Psique, 2013; 3(2):151-161 titucionais e individuais, como pertencentes a uma plano comum.

O sentido dessa multiplicidade complexa de indivíduos é o de que quanto mais nos abrirmos para a experimentação com pessoas e coisas, mais potentes seremos, melhor pensaremos e agiremos. Assim, podemos pensar que juntos podemos pensar e agir melhor.

Dos encontros que fazemos, é através nossa imaginação que deles tomamos conhecimento e atribuímos causas ao que experimentamos. Mas podemos facilmente nos enganar. O reino dos afetos é também o reino da imprevisibilidade. Por isso experimentamos, com relação aos outros seres humanos, de forma gratuita, muitos afetos diferentes e passíveis de flutuação. Spinoza define o amor no Escólio da proposição 13 da Ética III como "uma alegria com uma causa exterior" ou o ódio como "uma tristeza com uma causa exterior". Ele mostra que podemos desenvolver amores e ódios intensos em relação a quem não conhecemos, odiando quem odeia a quem amamos, ou o contrário, amando quem ama a quem amamos, configurando um mundo em que nunca somos ingênuos em nossas relações com outros seres humanos. Há um outro elemento que pode dirigir nossas apreciações: o fato desse alguém com quem nos defrontamos ser por nós considerado "semelhante" a nós. Podemos ter tristeza pela 
desgraça alheia no caso de consideramos o infeliz como um semelhante. Ou ficarmos indiferentes ou menos tristes se não houver essa semelhança (Ética III, prop. 22) Podemos até nos alegrar com a desgraça de quem odiamos, ou ainda estarmos indiferentes aos infortúnios vividos por quem consideramos diferente de nós. Essa experiência da semelhança é também constituída por nossa imaginação.

Através da imaginação nos inteiramos das relações que estabelecemos com nossos semelhantes e através dessas relações, experimentamos afetos que não são apenas nossos enquanto indivíduos, mas que correspondem a afetos vividos em coletividade. Isso ocorre porque somos contagiados pelos afetos daqueles a quem imaginamos que são nossos semelhantes. "Por imaginarmos que uma coisa semelhante a nós e que não nos provocou nenhum afeto é afetada de algum afeto, seremos, em razão dessa imaginação, afetados por um afeto semelhante" (Ética III, Prop. 27).

A partir da proposição 27 , a relação de objeto vai, com efeito, ser integrada à um processo no qual a necessidade autônoma é a da imitação dos afetos, que pela primeira vez no texto, se centra explicitamente no estudo das lógicas afetivas, nas maneiras de viver dos homens e por isso mesmo sobre o movimento perpétuo dos afetos que fazem com que os homens tendam a se aproximar (e a constituir um corpo comum), mas que lhes conduz necessariamente também, segunda as mesmas leis, a entrar em perpétuos conflitos (a). (Bove, 2006) ${ }^{1}$

Gabriel Tarde analisa a "lei da imitação dos afetos", no mesmo sentido de Spinoza, dando relevo ao contágio imitativos dos afetos como fenômeno humano e como meio de compreensão da vida coletiva. Também para Lordon, “a imitação é como um tijolo na formação de afetos coletivos compostos". (Lordon, 2010, p. 6). Verificamos também, na proposição 31 da parte III da Ética, "que cada um se esforça para que outros amem o que ele ama, e odeie quem ele odeia", o que poderia ser um obstáculo à experiência coletiva, não fossem as relações de semelhança que se estabelecem horizontalmente, de tal sorte que muitos possam ter um único objeto de amor ou de ódio.

Influenciamo-nos pelos afetos vividos por aqueles a quem consideramos semelhantes, tanto assim que se nossos semelhantes se entristecem, nos entristecemos também, ou se estão alegres, nos alegramos. A vida coletiva contribui, desse modo, para a superação de nossas tristezas, pois, mesmo estando tristes, por exemplo, pela morte de alguém, o contágio coletivo nos ajuda à recuperar nossa potência. Sozinhos, contamos apenas com nossos próprios afetos.

Podemos atribuir características positivas a alguém apenas porque um amigo nosso gosta dessa pessoa. E negativas, ao 
contrário, se é amiga de um inimigo nosso. Podemos também estender, como vimos, a todo um grupo a raiva que temos de um de seus integrantes. Se gostarmos de futebol, podemos ver com bons olhos o vizinho que é torcedor deste mesmo time, antes conhecê-lo. Em certos momentos da vida política brasileira, experimentamos esse sentimento de pertencimento, de comunidade. Assim, porém, a variação a que está sujeita a vida afetiva humana, determinada a partir dos encontros que fazemos com os objetos exteriores, nos traz também a possibilidade de estabelecer e também de romper os laços afetivos que estabelecemos com outros indivíduos.

Atribuímos de maneira fortuita a classificação de boa ou má às coisas, pois, cada um julga, antes de tudo, de acordo com seu afeto e não por alguma característica intrínseca à coisa, que faça com que a apreciemos. Mas como vivemos sempre cercados das pessoas que amamos (família, amigos próximos) ou semelhantes (os que vivem na mesma cidade, os da mesma profissão, os da mesma rua, etc.) então já não se trata de "cada um", mas temos também que considerar os afetos vividos pelos nossos semelhantes que podem nos afetar, tanto para o lado da potencialização quanto para o lado do medo.

Spinoza considera que os amantes e também o povo sob um governo vivem Rev. Polis e Psique, 2013; 3(2):151-161 alternando entre os afetos de esperança e medo. Referindo-se aos ódios e preconceitos aparentemente inexplicáveis, dirigidos a grupos e minorias, Spinoza diz que podemos ser afetados de alegria ou de tristeza por alguém que pertença "a um grupo social ou nacional diferente do seu", alegria ou tristeza que vem acompanhada da ideia genérica desse grupo como causa (Ética III, prop. 46). Desse modo, nunca somos neutros; a imaginação é como um filtro que está sempre presente nas relações que estabelecemos.

É pela via da imaginação que podemos estabelecer uma relação tal com outros homens, que podemos funcionar como "um só corpo e uma só mente", ultrapassando aquelas experiências particulares que frequentemente nos fazem entrar em conflito e disputas com eles. É certo que os governos também se utilizam dessa possibilidade de estabelecer essa relação na qual funcionamos como "um só corpo e uma só mente". A dominação política se exerce, em grande parte, através do domínio da imaginação. Também sob a ação do dispositivo da criminalização, tememos coletivamente aos bandidos que nos podem atacar ou aos vândalos infiltrados nas manifestações, após acompanhar o noticiário televisivo.

Spinoza aponta que os políticos sabem melhor manejar e reconhecer a afetividade humana, que está envolvida na po- 
lítica, do que os filósofos, que geralmente trazem um modelo, um ideal, a partir do qual pensam os fenômenos políticos e querem ajustar os indivíduos a ele. Por esse mesmo raciocínio, muitos estão desencantados com a política, por não serem as coisas tal como eles gostariam que fossem. Porém a política, para Spinoza, não se dá no plano dos ideais e sim na materialidade dos afetos humanos. A esperança e o medo são os principais afetos experimentados na vida social, através dos quais o estado civil governa. As artes da política se dariam a conhecer aos políticos hábeis, mais dotados que os filósofos dessa sabedoria sobre os afetos humanos.

Numa situação de medo, os homens podem aceitar um mal menor para evitar um mal maior que imaginam estar por vir. Podem ficar esperançosos de que no futuro possam comprar sua casa própria. Porém ao constatar que tal bonança custa a chegar, passam novamente a temer pelo futuro. Oscilando entre esses dois tipos de experiência, a esperança pode facilmente se transformar em decepção, se houver uma demora excessiva em atingir um sonho almejado. Por outro lado, o medo pode se transformar em esperança, caso um carioca acredite, por exemplo, que com a chegada de uma Unidade de Polícia Pacificadora a uma favela próxima, o bairro pode se tornar menos perigoso. $\mathrm{O}$ medo se esvanece e voltamos a ter Rev. Polis e Psique, 2013;3(2):151-161 esperança ou outro afeto alegre. É certo que um governo pela esperança é melhor do que um governo pelo medo, pois a esperança corresponde a um grau de potência maior. Constatamos também que os homens perseveram em suas lutas, quer com afetos de medo ou de esperança, que dizem respeito a diferentes graus de potência. Porém a fragilidade desses afetos, por sua capacidade de se transformarem constantemente, se traduz também na fragilidade constitutiva dos governos no que diz respeito à dominação que podem exercer.

Afetos alegres estão presentes em duas figuras da vida contemporânea: a submissão alegre ao consumo ou à suprema delícia de ter um emprego ou, por outro lado, o medo da violência, do terrorismo ou da criminalidade. Lordon (2010A, p. 87) chamou de "submissão alegre" o modo apaixonado ou afetivo como o capitalismo hoje consegue produzir submissão, apesar do visível retrocesso nas condições de trabalho e salário: a ampliação da jornada de trabalho, mesmo quando camuflada pelo uso do computador em casa, os baixos salários pagos, o esvaziamento dos sindicatos e a diminuição das greves, os empregos temporários, a perda do direito a férias, o sempre anunciado fim do décimo terceiro salário ... $\mathrm{Na}$ perspectiva positiva seguida por Spinoza frente a variação dos afetos humanos, podemos extrair, assim, uma consequência de impor- 
tância política: uma vez que a experiência afetiva humana está marcada pela variação, não podemos conceber que o medo coletivo, assim como a esperança possam se instalar de modo definitivo. Desse modo, se a instabilidade dos afetos pode ser vista como um sinal de imperfeição humana, ela também pode ser vista como um sinal de que a submissão, experimentada como efeito do dispositivo da criminalização, não pode ser eterna. Ela pode ser apenas como o amor para Vinícius de Moraes: eterna enquanto durar.

Spinoza, influenciado por Machiavel no Tratado Político, pensa que um dos afetos nos quais o medo pode se transformar é a revolta. Por isso podemos pensar que está sempre dada a possibilidade de um povo de superar sua situação de dominação. Saber como se dá essa superação seria responder à célebre pergunta spinozista - porque os homens lutam por sua servidão como se fosse sua liberdade? Neste senário precisamos sempre analisar os mecanismos imitativos que produzem afetos comuns que levam à submissão. Ou para retornarmos à uma questão colocada por Reich (2010), acompanhar os processos que fizeram com que as massas desejassem o fascismo .

Verificamos, assim, que lógicas de imitação levam com frequência à servidão, o que podemos comprovar examinando as múltiplas técnicas de submissão postas em ação a partir de palavras de ordem (Deleuze, 1995) que atravessam o coletivo, que podem ir no sentido do consumo, do medo à criminalidade, do regozijo quando um criminoso é castigado ou da inveja despertada pelo que acreditamos que os outros têm e que não temos. Um dos afetos tristes que podem surgir neste e noutros casos é o afeto de indignação. Apesar de ser um afeto triste, ele encerra uma positividade quando experimentado coletivamente, pois está a um passo da revolta. Para Machiavel, a quem Spinoza se referiu como "o arguto florentino" não é a opressão pura e simples que leva à revolta, mas a superação do medo ou sua transformação noutro tipo de afeto. Assim, podemos considerar que há uma distinção de grau entre medo e revolta e não de natureza, sendo o estado de rebelião um estado vizinho ao de medo (Lucchese, 2010).

Podemos entender a partir dessa vizinhança afetiva entre os afetos de medo e revolta, a súbita transformação da indignação experimentada pelo aumento vinte centavos no preço da passagem de ônibus na revolta popular que se estendeu a várias regiões do país simultaneamente, em junho de 2013. Ou a indignação experimentada na Tunísia a partir do episódio ocorrido em 2010, em que um jovem ateou fogo ao seu próprio corpo para protestar contra as condições de vida no país e não sobreviveu para ver a revolta que se produziu e se 
estendeu, por esse tipo contágio afetivo, ao Egito e outros países árabes.

Para Milton Santos (2001), neste ponto coincidindo com o pensamento de Deleuze (1990), algumas condições estão dadas no capitalismo atual para que imensas multidões se formem: a concentração urbana, o fato de muitos estarem vivendo uma situação de escassez, desde aqueles que historicamente já a viviam, até os novos pobres, ou os setores da classe média que a experimentam agora, deserdados da condição mais favorável que o milagre econômico da década de 70, no caso do Brasil, os teria alçado. De par com essa ascensão das massas, que os recentes acontecimentos da crise europeia e da primavera árabe tão bem ilustram, percebemos a ação de dispositivos de controle que embora poderosos, não têm podido impedir esse novo protagonismo da multidão no contemporâneo.

O otimismo de Milton Santos dizia respeito principalmente a possibilidades que estão presentes no momento atual e que os fatos estão ilustrando: o incremento dos contatos horizontais no sentido da expansão - a utilização das tecnologias (celulares, internet) no sentido da potencialização do coletivo, e a experiência de viver o que Viviane Forrester (1997) descreveu como "horror econômico", referindo às mutações ocorridas no contexto do trabalho no capitalismo mundial. Porém mesmo nesse quadro, verificamos que o dispositivo da criminalização vem sendo pouco afetado, e que sua ação silenciosa e ao mesmo tempo ruidosa prossegue, no sentido de desfazer os laços sociais ou enfraquecê-los, aumentando o medo e a desconfiança mútua, a inveja, o espírito de vingança, entre outros afetos negativos. E eis que surgem ou se reeditam certas categorias, forjadas a partir da antiga noção de periculosidade, atualizadas por designações como a de vândalos, baderneiros, entre outras.

Nossa questão passa a ser, não tanto analisar os processos pelos quais o dispositivo da criminalização gera o medo coletivo e a submissão, mas compreender o que impede que o medo se transforme em revolta ou em que condições pode ocorrer essa transformação, uma vez que entre os afetos de medo e revolta existe essa proximidade. Os efeitos do dispositivo da criminalização poderiam ser considerados tão transitórios quanto o medo e desse modo constatamos sua fragilidade, apesar de todo o seu aparato ostensivo e espetacular e da apesar da repetição exaustiva e monótona de fatos violentos que chegam até nós através dos meios de comunicação.

Qual o alcance real das pílulas de medo destiladas diariamente pelo dispositivo da criminalização? Sua monótona repetição revela a fragilidade desse dispositivo, face à transitoriedade dos afetos humanos. 
Porém temos que considerar que dispositivo da criminalização funciona ao lado de outros dispositivos que agem sobre o coletivo. E é claro, há as armas e a força bruta, porém nem mesmo elas podem explicar totalmente a paralisia e a submissão. Os psicólogos que trabalham em prisões sabem que não são apenas as grades que mantém os homens presos, pois com frequência, um número muito pequeno de agentes penitenciários é suficiente para manter uma massa de homens atrás das grandes. Temos sempre que levar em conta, para entender os mecanismos que levam à submissão, as lógicas afetivas e os processos de produção de subjetividades.

No capitalismo atual estão dadas, como vimos, condições históricas que favorecem o contágio afetivo e a uniformização imitativa num grau talvez inusitado na história da espécie humana. No entanto, é visível a ação de vários dispositivos de controle social, como forças contrárias à potencialidade política da multidão. As instituições têm o poder de homogeneizar afetos, tanto tristes quanto alegres. Porém novos meios técnicos favorecem a comunicação horizontal em amplos setores e os movimentos sociais organizados via internet e celular têm ilustrado este fato. Condições históricas favorecem os laços horizontais, no sentido da solidariedade e da aliança. Porém forças poderosas agem noutro sentido, o das relações Rev. Polis e Psique, 2013;3(2):151-161 verticais, hierarquizadas e também na produção do comodismo, na busca de segurança e na produção de dependências de vários tipos. É nesse ideal de comodismo por muitos compartilhado, no sonho de viver uma vida sem conflitos, que deveremos buscar as razões pelas quais, não obstante à possibilidade sempre presente de que os afetos humanos se transformem, eles se cristalizem na submissão e no medo por longos períodos. Muitos querem viver protegidos - quer por um emprego seguro, quer por policiais armados, pelas grades de um condomínio... Enquanto um número cada vez maior passa a existência inteira atrás das grades. $\mathrm{Na}$ perspectiva de Spinoza, o isolamento implicará sempre na redução da sua potência humana, quer individual, quer coletiva.

\section{Notas}

${ }^{1}$ A tradução é minha. À partir de la proposition 27 , la relation d'objet va, en effet, être intégrée à un processus dont la nécessité autonome est celle de l'imitation des affects ce qui, pour la première fois dans le texte, recentre explicitement de fait l'étude des logiques affectives sur les manières de vivre des hommes, et par là même sur le mouvement perpétuel des affects qui font que les hommes tendent à se rapprocher (et à constituer un corps commun) mais qui les conduit nécessairement aussi, selon 
les mêmes lois, à entrer dans de perpétuels conflits.) Bove, Ética III.

\section{Referências}

Bove, L. (2010) Espinosa e a Psicologia Social. Ensaios de ontologia política e antropogênese. Belo Horizonte: Autêntica. (2006) Éthique III. Em Moreau, P.F. et Ramond, C. (orgs) Lectures de Spinoza, Paris: Ellipses. (pp. 109131).

(2002) Introduction. La Prudence des Corps. Du physique au politique. Em Spinoza. Traité Politique. Paris: Le livre de poche. (pp. 9-101).

Deleuze, G. (1990) Post-scriptum sur les sociétés de contrôle. Em Deleuze, G. Pourparlers. Paris: Minuit.

Deleuze, G., Guattari, F. (1976) O AntiÉdipo: Capitalismo e Esquizofrenia. Rio de Janeiro: Imago.

Sobre Alguns Regimes de Signos. (1995) Mil Platôs: Volume 1. São Paulo: Editora 34.

Forrester, V. (1997). O Horror Econômico. São Paulo: Unesp.

Lordon, F. (2010A). Capitalisme, désir et servitude. Paris: La Fabrique. (2010). La puissance des institutions. Revue du Mauss permanente.
Disponível em http://hyperspinoza. caute.1autre.net/?debut $\underline{\text { actu }=5 \# \text { pagination_actu }}$

Lucchese, P. del. (2010) Tumultes et indignation. Paris: Amsterdam

Rauter, C. (2009) Clínica e violência: construções e problematizações par uma clínica do contemporâneo. Em Tedesco, S. e Nascimento, M.L. (Orgs.) Ética e Subjetividade. Porto Alegre: Sulina, (pp. 60-73).

Reich, W. (2001) Psicologia das Massas do Fascismo. São Paulo: Martins Fontes. (obra originalmente publicada em 1933)

Santos, Milton. (2001) Por Uma Outra Globalização. Rio de Janeiro: Record.

Spinoza, B. de (2008) Ética. Belo Horizonte, Autêntica. (2009).Tratado Político. São Paulo: Martins Fontes.

Cristina Rauter: Professora Titular de Psicologia Social e Institucional, Universidade Federal Fluminense. Doutora em Psicologia Clínica. Coordenadora do Núcleo Transdisciplinar Subjetividades, Violências e Criminalização, Uff.

E-mail: rautercristinamair02@gmail.com

Recebido em: 02/11/2013 - Aceito em: 23/03/2014 